\title{
Antibiotic activity of telithromycin and comparators against bacterial pathogens isolated from 3,043 patients with acute exacerbation of chronic bronchitis
} Sanjay Sethi*1, Antonio Anzueto ${ }^{2}$ and David J Farrell ${ }^{3}$

\author{
Address: ${ }^{1}$ University at Buffalo SUNY, Buffalo NY, USA, 2South Texas Veterans Health Care System, Audie L. Murphy Memorial Veterans Hospital \\ Division, San Antonio, USA and ${ }^{3}$ GR Micro Limited, London, UK \\ Email: Sanjay Sethi* - ssethi@buffalo.edu; Antonio Anzueto - anzueto@uthscsa.edu; David J Farrell - d.farrell@grmicro.co.uk \\ * Corresponding author
}

Published: 08 March 2005

Annals of Clinical Microbiology and Antimicrobials 2005, 4:5 doi:10.1 I86/1476-07II-4-5

This article is available from: http://www.ann-clinmicrob.com/content/4/I/5

(c) 2005 Sethi et al; licensee BioMed Central Ltd.

This is an Open Access article distributed under the terms of the Creative Commons Attribution License (http://creativecommons.org/licenses/by/2.0), which permits unrestricted use, distribution, and reproduction in any medium, provided the original work is properly cited.
Received: 08 February 2005

Accepted: 08 March 2005

\begin{abstract}
Background: Antimicrobial therapy is considered an important component in the medical management of most patients with acute exacerbation of chronic bronchitis (AECB). The three predominant bacterial species isolated are nontypeable Haemophilus influenzae, Moraxella catarrhalis, and Streptococcus pneumoniae. Staphylococcus aureus is also frequently isolated while atypical bacteria are thought to cause up to 10\% of exacerbations. Antibacterial resistance is increasing worldwide and little surveillance data exist concerning pathogens isolated from patients with AECB.

Methods: This study examines the prevalence of antibacterial resistance in isolates obtained from patients with clinically diagnosed AECB. A total of 3043 isolates were obtained from 85 centres in 29 countries, between 1999-2003, and were tested against the new ketolide telithromycin and a panel of commonly used antibiotics.

Results and Discussion: Of the $S$. pneumoniae isolates, $99.9 \%$ were susceptible to telithromycin, but only $71 \%$ were susceptible to erythromycin and $75.3 \%$ to penicillin. Of the $H$. influenzae isolates, $99.6 \%$ were susceptible to telithromycin. $11.7 \%$ of these isolates produced $\beta$-lactamase. Almost $10 \%$ of S. pneumoniae were multidrug-resistant; $99.0 \%$ of these isolates were susceptible to telithromycin. Telithromycin also demonstrated good in vitro activity against $M$. catarrhalis $\left(\mathrm{MIC}_{90}=\right.$ $0.12 \mathrm{mg} / \mathrm{L}$ ) and was the most active compound against methicillin-susceptible $S$. aureus $(98.9 \%$ susceptible).

Conclusion: Telithromycin demonstrated similar or better activity against the bacterial species investigated than the other agents, with the most complete coverage overall. These species are the predominant causative bacterial pathogens in $A E C B$ and thus the spectrum of activity of telithromycin makes it a potential alternative for the empirical treatment of $A E C B$.
\end{abstract}

\section{Introduction}

The World Health Organization (WHO) estimates that chronic obstructive pulmonary disease (COPD) is the fourth leading cause of death worldwide. In the year 2000, it was estimated that 2.74 million people died from COPD worldwide [1]. COPD is defined by the presence of 
irreversible or partially irreversible airway obstruction in patients with chronic bronchitis or emphysema $[2,3]$. The disease is characterized by recurrent (1-4 per year) acute exacerbations of chronic bronchitis (AECB), defined by a subjective increase from baseline of one or more symptoms including shortness of breath, cough, sputum production, and sputum purulence [4]. The precipitating factors for AECB have been extensively researched and determined to be heterogeneous with complex aetiology [5-10].

Results from a number of placebo-controlled clinical investigations have demonstrated that antibacterial agents are of significant clinical benefit in the treatment of AECB, particularly for those patients with at least two of the three cardinal symptoms of AECB (worsening dyspnoea, increased sputum volume, and increased sputum purulence) and/or severe airway obstruction [11-13]. Other clinical trials measuring non-traditional endpoints have shown that antibiotic therapy reduces the time to symptom resolution and has long-term benefits including greater intervals between episodes of exacerbation $[14,15]$. Consequently, antibiotic therapy is considered an important component in the medical management of patients with AECB.

Bacteria can be isolated from $40-60 \%$ of sputum samples of patients experiencing AECB [16]. The three predominant bacterial species isolated are non-typeable Haemophilus influenzae, Moraxella catarrhalis, and Streptococcus pneumoniae. Other less frequently isolated potential pathogens are Gram-negative enterobacteria, Haemophilus parainfluenzae, Staphylococcus aureus, and Pseudomonas aeruginosa. Gram negative enterobacteria and Pseudomonas aeruginosa are more frequently isolated in patients with severe underlying disease [10]. Viral infections are present in approximately $30 \%$ of exacerbations, Mycoplasma pneumoniae in $1-10 \%$, and Chlamydophila pneumoniae in $4-5 \%$ (serologically identified) [6-10].

Amoxycillin, ampicillin, sulfamethoxazole-trimethoprim (trimethoprim-sulphamethoxazole), tetracyclines, and erythromycin are considered first-line antimicrobial therapy for AECB [17]. The clinical utility of these agents is, however, being hampered by the increasing global spread of pathogens with resistance to one or more of these agents. Up to $40 \%$ of $H$. influenzae isolates and more than $90 \%$ of $M$. catarrhalis isolates produce $\beta$-lactamase and this limits the value of penicillins and some other $\beta$ lactams [18]. Furthermore, resistance to penicillin and macrolides has spread rapidly among isolates of $S$. pneumoniae [19]. Other agents used include extended spectrum cephalosporins, amoxycillin/clavulanate, azithromycin, clarithromycin, and levofloxacin.
Table I: Geographical distribution of isolates from AECB patients used in this study

\begin{tabular}{llll}
\hline Area & Countries & Centres & Isolates \\
\hline North America & 2 & 4 & 319 \\
South America & 6 & 14 & 427 \\
Europe & 13 & 41 & 1847 \\
Australasia & 6 & 19 & 437 \\
South Africa & 1 & 6 & 13 \\
\hline Totals & 29 & 85 & 3043 \\
\hline
\end{tabular}

Telithromycin is the first ketolide available for clinical use. Derivatives of erythromycin-A, the ketolides, like the macrolides, exert their antimicrobial action by binding to the bacterial ribosome. Although both macrolides and ketolides bind strongly to a region of domain $\mathrm{V}$ in the $23 \mathrm{~S}$ rRNA of the ribosome, telithromycin has additional strong binding to a region in domain II to which the macrolides bind weakly [20]. Ketolides are also poor substrates for the efflux pump (mefA) responsible for macrolide resistance in S. pneumoniae [21]. Consequently, telithromycin has been found to have potent activity against macrolide resistant $S$. pneumoniae with methylase, efflux or ribosomal mutations as the mechanisms of resistance [22,23].

There is a need for alterative therapeutic options for the treatment of AECB and surveillance data are needed to help determine the suitability of new agents. The PROTEKT (Prospective Resistant Organism Tracking and Epidemiology for the Ketolide Telithromycin) study is an international, longitudinal, antibacterial resistance surveillance study, which was initiated in 1999 to monitor the spread of resistance among respiratory tract pathogens worldwide. Here we analyze the in vitro antimicrobial activity of bacterial isolates obtained from patients clinically diagnosed with AECB in 3 consecutive years of the PROTEKT study. Using these data, and previously published clinical data, the potential role of telithromycin in the treatment of AECB will be discussed.

\section{Materials and Methods \\ Patients and bacterial isolates}

Details of the study design, including the selection of patients and the methodology for the identification of isolates and their storage in the PROTEKT study has been described previously [24]. Isolates in this study were obtained from patients diagnosed with AECB from in 85 centres in 29 countries (Table 1). To be included in this analysis, an isolate was deemed pathogenic in AECB by clinical and laboratory findings. Isolates were only acceptable if the patient was $\geq 30$ years old and the specimen 
Table 2: Distribution of specimen types by species for the 3043 bacterial pathogens described in this study

\begin{tabular}{lllllll}
\hline Specimen & S. pneumoniae & H. influenzae & M. catarhalis & S. aureus & H. parainfluenzael & Total [n (\%)] \\
\hline Sputum & 832 & 895 & 492 & 219 & 43 & $2481(81.5)$ \\
BAL2 & 144 & 135 & 44 & 66 & 17 & $406(13.4)$ \\
Blood & 99 & 7 & 0 & 50 & 0 & $156(5.1)$ \\
\hline Total [n (\%)] & $1075(35.3)$ & $1037(34.1)$ & $536(17.6)$ & $335(11.0)$ & $60(2.0)$ & $3043(100)$ \\
\hline
\end{tabular}

IOnly isolated in the first year of the study

${ }^{2}$ Bronchoalveolar lavage

was obtained from blood, bronchoalveolar lavage (BAL), or sputum. Isolates from patients diagnosed with AECB obtained from other sites (e.g., ear, throat, nasopharynx) and isolates obtained from patients $<30$ years of age were excluded from this analysis because AECB is more likely to be present in patients $\geq 30$ years of age and the responsible bacterial pathogen is more likely to be correctly isolated from the blood, BAL, or sputum.

In Year 1 (1999-2000), each centre had a quota of 60 isolates of $S$. pneumoniae, $40 \mathrm{H}$. influenzae, $15 \mathrm{H}$. parainfluenzae, $20 \mathrm{M}$. catarrhalis, 25 Streptococcus pyogenes and $20 \mathrm{~S}$. aureus to collect. In years $2(2000-2001)$ and 3 (20012002), H. parainfluenzae were not collected and 15 extra isolates of $S$. pneumoniae were collected instead.

\section{Antimicrobial testing}

The comparator agents used were four $\beta$-lactams; penicillin (for S. pneumoniae and S. aureus), ampicillin (for $H$. influenzae, H. parainfluenzae and M. catarrhalis), amoxycillin/clavulanate, and cefuroxime, three macrolides/azalides; erythromycin, clarithromycin, and azithromycin, the folate synthesis inhibitor; trimethoprim-sulphamethoxazole, the tetracycline; tetracycline and a fluoroquinolone, levofloxacin.

Minimum inhibitory concentrations (MIC) of each antibacterial were determined using the National Committee for Clinical and Laboratory Standards (NCCLS) broth microdilution methodology and lyophilised microtitre plates (Sensititre, Trek Diagnostics) at a central laboratory (GR Micro Ltd., London, UK) [26]. NCCLS breakpoints $[25,26]$ were used to interpret the MIC data and to determine susceptibility status. The NCCLS breakpoints for telithromycin for $S$. pneumoniae and for $S$. aureus are $\leq 1 \mathrm{mg} /$ $\mathrm{l}$ is susceptible, $2 \mathrm{mg} / \mathrm{l}$ is intermediate, and $\geq 4 \mathrm{mg} / \mathrm{l}$ is resistant, and for $H$. influenzae $\leq 4 \mathrm{mg} / \mathrm{l}$ is susceptible, 8 $\mathrm{mg} / \mathrm{l}$ is intermediate, and $\geq 16 \mathrm{mg} / \mathrm{l}$ is resistant [27].

\section{Results}

A total of 3043 bacterial pathogens were isolated from patients in 29 countries around the world, with by far the largest number of specimens (1841, 60.5\%) coming from Europe (Table 1). Percentage of isolates by country were as follows: Argentina 8.0\%, Australia 1.1\%, Austria 0.6\%, Brazil $4.0 \%$, Canada $9.1 \%$, China $1.7 \%$, Colombia $0.1 \%$, Ecuador $0.6 \%$, Eire $0.03 \%$, France $3.4 \%$, Germany $14.3 \%$, Hungary $1.2 \%$, Indonesia $0.03 \%$, Italy $18.9 \%$, Japan $10.0 \%$, Mexico $1.3 \%$, Poland $10.2 \%$, Portugal $2.8 \%$, Russia $0.2 \%$, South Africa $0.4 \%$, South Korea $0.9 \%$, Spain $5.3 \%$, Sweden $0.4 \%$, Switzerland $0.6 \%$, Taiwan $0.7 \%$, Turkey $0.3 \%$, United Kingdom 2.4\%, United States 1.4\%, Venezuela $0.1 \%$.

Of these isolates identified as causative pathogens for bacterial AECB, $S$. pneumoniae and $H$. influenzae formed the majority (1075 and 1037 respectively), followed by $M$. catarrhalis (536) (Table 2). Patients were predominantly male $(63.5 \%)$, with $47.5 \%$ of patients belonging to the (30-64) year age group and $52.5 \%$ in the $>64$ year old age group. No difference in the distribution of pathogens by age group was observed (data not shown).

Table 3 shows the range of MIC values, the $\mathrm{MIC}_{50}$ and $\mathrm{MIC}_{90}$ of the various agents against the five species. Where breakpoints were available the percentage of isolates to the various agents is also included. Telithromycin had similar or better in vitro susceptibility than the comparator agents against all of these species. Activity against $S$. pneumoniae was particularly good, with telithromycin being the most active agent; $99.9 \%$ of isolates were classified as susceptible and the $\mathrm{MIC}_{90}(0.12 \mathrm{mg} / \mathrm{L})$ was substantially lower than all other compounds tested.

One hundred and three (9.6\%) S. pneumoniae isolates (from 51 and 53 patients in the 30-64 and >64 year old age groups respectively)) were resistant to both penicillin (MIC $\geq 2 \mathrm{mg} / \mathrm{L}$ ) and erythromycin (MIC $\geq 1 \mathrm{mg} / \mathrm{L}$ ) and this was reflected in resistance to amoxycillin, cefuroxime, clarithromycin and azithromycin also (Table 4). These isolates were found in 35 centres in 16 countries. Sixty of these resistant isolates were also resistant to both trimethoprim-sulphamethoxazole and tetracycline. Both telithromycin and levofloxacin had good activity against these 
Table 3: In vitro activity of antibacterial agents against 3043 bacterial pathogens isolated from patients with AECB and \% susceptibilities to antibacterial agents.

\begin{tabular}{|c|c|c|c|c|c|c|c|}
\hline \multirow[t]{2}{*}{ Organism } & \multirow[t]{2}{*}{ Antibacterial } & \multicolumn{3}{|l|}{ MIC mg/l } & \multicolumn{3}{|c|}{$\%$ susceptible } \\
\hline & & range & 50 & 90 & total & MSSA & MRSA \\
\hline \multirow[t]{10}{*}{ S. pneumoniae $\mathrm{N}=1075$} & Telithromycin & $0.004-2$ & 0.015 & 0.12 & 99.9 & & \\
\hline & Azithromycin & $0.03->64$ & 0.12 & $>64$ & 71.2 & & \\
\hline & Clarithromycin & $0.015->32$ & 0.03 & $>32$ & 71 & & \\
\hline & Erythromycin & $0.03->64$ & 0.06 & $>64$ & 71 & & \\
\hline & Penicillin & $0.008-8$ & 0.03 & 2 & 75.3 & & \\
\hline & Amox/clavulanate & $0.015-8$ & 0.03 & 2 & 96.1 & & \\
\hline & Cefuroxime & $0.015-16$ & 0.03 & 2 & 82.2 & & \\
\hline & Trimethoprim-sulphamethoxazole & $0.12-32$ & 0.25 & 8 & 62 & & \\
\hline & Tetracycline & $0.12-32$ & 0.25 & 32 & 69.6 & & \\
\hline & Levofloxacin & $0.5->32$ & 1 & 1 & 98.9 & & \\
\hline \multirow[t]{10}{*}{ H. influenzae $N=1037$} & Telithromycin & $0.002-16$ & 1 & 2 & 99.6 & & \\
\hline & Azithromycin & $0.06-32$ & 1 & 2 & 99.7 & & \\
\hline & Clarithromycin & $0.25->64$ & 8 & 16 & 82.4 & & \\
\hline & Erythromycin & $0.25->64$ & 4 & 8 & -2 & & \\
\hline & Ampicillin & $0.12-32$ & 0.25 & 16 & 87.3 & & \\
\hline & Amox/clavulanatel & $0.12-4$ & 0.5 & 1 & 100 & & \\
\hline & Cefuroxime & $0.12-16$ & I & 2 & 99.5 & & \\
\hline & Trimethoprim-sulphamethoxazole & $0.03-32$ & 0.06 & 4 & 80.7 & & \\
\hline & Tetracycline & $0.12-32$ & 0.5 & 1 & 97.4 & & \\
\hline & Levofloxacin & $0.008-8$ & 0.015 & 0.015 & 99.8 & & \\
\hline \multirow[t]{10}{*}{ M. catarrhalis $N=536$} & Telithromycin & $0.004-0.5$ & 0.06 & 0.12 & & & \\
\hline & Azithromycin & $0.06-0.25$ & 0.06 & 0.06 & & & \\
\hline & Clarithromycin & $0.25-0.5$ & 0.25 & 0.25 & & & \\
\hline & Erythromycin & $0.25-1$ & 0.25 & 0.25 & & & \\
\hline & Ampicillin & $0.12-32$ & 8 & 16 & & & \\
\hline & Amox/clavulanatel & $0.12-0.5$ & 0.12 & 0.25 & & & \\
\hline & Cefuroxime & $0.12-16$ & I & 2 & & & \\
\hline & Trimethoprim-sulphamethoxazole & $0.06-4$ & 0.25 & 0.5 & & & \\
\hline & Tetracycline & $0.12-32$ & 0.25 & 0.5 & & & \\
\hline & Levofloxacin & $0.008-0.06$ & 0.03 & 0.03 & & & \\
\hline \multirow[t]{10}{*}{ S. aureus $\mathrm{N}=335$} & Telithromycin & $0.03->32$ & 0.06 & $>32$ & 85.1 & 98.9 & 24.2 \\
\hline & Azithromycin & $0.12->64$ & 1 & $>64$ & 70.4 & 84.2 & 9.7 \\
\hline & Clarithromycin & $0.03->32$ & 0.25 & $>32$ & 70.4 & 84.2 & 9.7 \\
\hline & Erythromycin & $0.12->64$ & 0.25 & $>64$ & 70.4 & 84.6 & 9.7 \\
\hline & Penicillin & $0.008-8$ & 4 & 8 & 23.6 & 28.9 & 0 \\
\hline & Amox/clavulanatel & $0.06-8$ & 0.5 & 8 & 83.1 & 100 & 0 \\
\hline & Cefuroxime & $0.12-16$ & 1 & 16 & 81.2 & 100 & 0 \\
\hline & Trimethoprim-sulphamethoxazole & $0.12-32$ & 0.12 & 0.25 & 94.9 & 97.4 & 83.9 \\
\hline & Tetracycline & $0.12-32$ & 0.5 & 32 & 84.8 & 92.7 & 50 \\
\hline & Levofloxacin & $0.5-64$ & 0.5 & 8 & 76.7 & 81.7 & 6.5 \\
\hline \multirow[t]{10}{*}{ H. parainfluenzae $\mathrm{N}=60$} & Telithromycin & $0.06-4$ & 1 & 2 & 100 & & \\
\hline & Azithromycin & $0.06-2$ & 0.5 & 1 & 100 & & \\
\hline & Clarithromycin & $0.25-16$ & 4 & 8 & 93.3 & & \\
\hline & Erythromycin & $0.5-8$ & 2 & 4 & -2 & & \\
\hline & Ampicillin & $0.12-32$ & 0.25 & 1 & 90 & & \\
\hline & Amox/clavulanatel & $0.12-2$ & 0.5 & 1 & 100 & & \\
\hline & Cefuroxime & $0.12-4$ & 0.25 & 0.5 & 100 & & \\
\hline & Trimethoprim-sulphamethoxazole & $0.03-32$ & 0.03 & I & 88.3 & & \\
\hline & Tetracycline & $0.12-16$ & 0.5 & 4 & 88.3 & & \\
\hline & Levofloxacin & $0.008-8$ & 0.015 & 0.06 & 98.4 & & \\
\hline
\end{tabular}

'Amox/clavulanate $=$ Amoxycillin/clavulanate

${ }^{2}$ No CLSI interpretive criteria for erythromycin and Haemophilus spp. 
Table 4: Antibacterial activity against 103 Streptococcus pneumoniae isolates with combined macrolide and penicillin resistance

\begin{tabular}{llll}
\hline Antibacterial & \% susceptible & \% intermediate & \% resistant \\
\hline Telithromycin & 99.0 & 1.0 & 0.0 \\
Azithromycin & 0 & 0 & 100 \\
Clarithromycin & 0 & 0 & 100 \\
Erythromycin & 0 & 0 & 100 \\
Penicillin & 0 & 0 & 100 \\
Amoxycillin & 0 & 0 & 100 \\
Amoxycillin-clavulanate & 72.8 & 13.6 & 13.6 \\
Cefuroxime & 1.0 & 1.0 & 98.0 \\
Trimethoprim-sulphamethoxazole & 19.4 & 16.5 & 64.1 \\
Tetracycline & 11.7 & 0.0 & 88.3 \\
Levofloxacin & 98.1 & 0.0 & 1.9 \\
\hline
\end{tabular}

isolates, $99 \%$ susceptibility to telithromycin and $98.1 \%$ to levofloxacin. The $\mathrm{MIC}_{50}$ and $\mathrm{MIC}_{90}$ values for telithromycin in this population were $0.06 \mathrm{mg} / \mathrm{L}$ and $0.5 \mathrm{mg} / \mathrm{L}$, respectively.

Over $99 \%$ of $H$. influenzae isolates were susceptible to amoxycillin-clavulanate, cefuroxime, telithromycin, azithromycin, and levofloxacin. Tetracycline also had good activity with $97.4 \%$ of isolates susceptible. Only $11.7 \%$ of $H$. influenzae isolates produced $\beta$-lactamase. There were only 60 isolates of $H$. parainfluenzae and $100 \%$ of these were susceptible to four of the eight compounds tested, telithromycin, amoxycillin/clavulanate, cefuroxime and azithromycin. Trimethoprim-sulphamethoxazole and tetracycline were the least active compounds. In terms of MICs, levofloxacin, azithromycin and telithromycin were the most potent compounds against $M$. catarrhalis with $\mathrm{MIC}_{90}$ values of $0.03 \mathrm{mg} / \mathrm{l}, 0.06 \mathrm{mg} / \mathrm{l}$ and $0.12 \mathrm{mg} / \mathrm{l}$ respectively.

There are currently no interpretative NCCLS guidelines available for M. catarrhalis to allow classification into susceptible or resistant categories.

The total number of isolates of $S$. aureus was 335 and of these only 62 were resistant to methicillin (MRSA). Trimethoprim-sulphamethoxazole was the most active compound overall, with $94.9 \%$ of all isolates being susceptible. Telithromycin and tetracycline were the next most active with $85.1 \%$ and $84.8 \%$ of all isolates susceptible. Telithromycin was the most active compound against the MSSA isolates, with $98.9 \%$ being susceptible. The susceptibility of MSSA to tetracycline and trimethoprim-sulphamethoxazole was $92.7 \%$ and $97.4 \%$ susceptible respectively. These three compounds were the only ones to have activity against the MRSA isolates (trimethoprim-sulphamethoxazole $83.9 \%$, tetracycline $50 \%$ and telithromycin $24.2 \%$ ). Less than $10 \%$ of the MRSA isolates were susceptible to the remainder of the compounds.

\section{Discussion}

The primary cause of COPD is exposure to tobacco smoke, the major risk factor being cigarette smoking. The demography of the disease in this study and others reflects this, as the majority of patients in this analysis were male and half were elderly ( $>64 \mathrm{yrs}$ of age) (2). S. pneumoniae is most frequently isolated in the least severe cases of AECB, whereas $H$. influenzae is more commonly isolated from moderate to severe cases, with $P$. aeruginosa occurring in severe hospitalised cases [28]. Telithromycin does not have good activity against Pseudomonas spp. (GR Micro Limited, data on file, internal report number 141-02-99) and hence may not be an appropriate empirical therapeutic option for AECB patients with severe underlying disease who are hospitalized for an acute exacerbation.

Whether the isolation of a pathogen during AECB represents an infection responsible for the exacerbation has been debated for many years [29-31]. Bacteria have been isolated almost as frequently from patients with stable COPD as those with an AECB, and clinical trials of antibiotic therapy in AECB show contradictory and sometimes unconvincing results [30]. The presence of bacteria in the lower airways is, however, regarded as abnormal since these airways are sterile in healthy adults, and it has been hypothesized that the presence of bacteria in stable COPD represents a low-grade smouldering infection. In addition, a recent study has shown that infection with different strains of pathogens that are new to the patient is associated with development of exacerbation $[32,33]$.

Amoxycillin-clavulanate, azithromycin, and levofloxacin have been shown to be effective in the treatment of AECB, however, there is concern regarding their long-term usefulness, because of the development of resistance to these 
agents among the causative pathogens [34,35]. Telithromycin has a more focused spectrum of activity than the $\beta$ lactams and the fluoroquinolones; it is specifically targeted against pathogens causing community-acquired respiratory disease, including those most commonly associated with AECB. In addition, it is active against penicillin- and macrolide-resistant strains of $S$. pneumoniae and hence offers a viable potential option for the empiric treatment of AECB in non-hospitalised patients [36].

The data in this study demonstrate that telithromycin has high in vitro activity against the commonest bacterial pathogens causing AECB. These data also show that telithromycin has the highest overall activity against bacterial isolates from patients with $\mathrm{AECB}$, regardless of species. Almost $10 \%$ of S. pneumoniae isolated were resistant to penicillin, macrolides, and at least one of the other antibiotics tested, with only telithromycin and levofloxacin retaining high activity against these isolates (99.0\% and $98.1 \%$, respectively). The validity of this finding is strengthened as the isolates were obtained from a large number of patients over a wide geographical distribution.

Although atypical pathogens were not examined in the PROTEKT study, telithromycin has been shown to have superior activity in vitro against Chlamydophila pneumoniae to the other macrolides with the exception of clarithromycin and has similar activity to the fluoroquinolones [37]. In guinea pig models, telithromycin had better activity than erythromycin against Legionella pneumophila infections [38]. In vitro, the activity of telithromycin against $L$. pneumophila was similar to levofloxacin but better than erythromycin [38]. $\beta$-lactams and cephalosporins have no activity against Mycoplasma pneumoniae as this species lacks a typical bacterial cell wall, the site of activity for these drugs. Telithromycin has been found to have higher activity than doxycycline and levofloxacin against $M$. pneumoniae [39]. As the atypical pathogens can represent up to $10 \%$ of infections associated with AECB, the efficacy of telithromycin against these pathogens could be a consideration in the selection of empiric therapy for AECB.

Telithromycin has been shown to penetrate into respiratory tissues well [40]. The concentration of telithromycin in alveolar macrophages and epithelial lining fluid exceeds that of plasma markedly and remains at therapeutic levels for 24 hours after dosing. Bactericidal levels are also maintained in plasma. A good post-antibiotic effect has also been observed [41]. Telithromycin causes only moderate ecological disturbance to oral and intestinal flora comparable to that associated with clarithromycin and it does not significantly increase the development of resistance in the normal flora, although the MIC of oral streptococci can be slightly raised [42].
Telithromycin can be administered once a day for AECB. Clinical studies have demonstrated that $800 \mathrm{mg}$ administered once daily for 5 days was as effective and well tolerated as a 10-day course of amoxycillin/clavulanate (500/ $125 \mathrm{mg} 3$ times daily for 10 days), cefuroxime axetil (500 mg twice daily for 10 days) or clarithromycin (500 mg twice daily for 10 days) [43]. Other clinical studies have also confirmed the safety and tolerability of telithromycin $800 \mathrm{mg}$ administered for 5 - 10 days [44]. Once a day dosing schedules and shorter courses may promote patient adherence to therapy, and this in turn could delay the development of resistance.

Although this study provides valuable information on the overall antimicrobial profile of bacteria causing AECB, care should be taken when interpreting data related to specific demographics. The prevalence of species could not be calculated in this study as a major limitation, inherent to most surveillance studies, is the requirement for collecting centres to fulfil a specified quota of isolates over a defined time period ( 1 year). If, for instance, a centre managed to fulfil the quota for $S$. pneumoniae isolates from patients with community-acquired pneumonia, it could then only send $H$. influenzae from patients with AECB to fulfil the quota for this organism. In addition, atypical pathogens were not sampled and they can represent up to $10 \%$ of the causative pathogens [28].

In summary, the data presented here demonstrate that telithromycin has good in vitro activity against $H$. influenzae, $S$. pneumoniae, and M. catarrhalis, respiratory pathogens commonly isolated in AECB. It is as active as or more active than agents that are currently used in this clinical setting. Additionally, although not shown here, telithromycin has better in vitro activity against atypical pathogens than other agents; an important advantage in this clinical setting as these pathogens may represent $10 \%$ of AECB associated infections.

The development of resistance will always be a threat to the usefulness of antibacterial compounds, however surveillance studies such as PROTEKT allow the rapid detection and characterization of resistance mechanisms and highlight the need for and examine the in vitro efficacy of newer antibacterial agents. Providing careful surveillance for the development of resistance is maintained, telithromycin currently offers a useful agent in the treatment of AECB.

\section{Acknowledgements}

We are grateful to our colleagues worldwide for the supply of bacterial isolates as part of the PROTEKT study and the GR Micro PROTEKT team who performed the MIC testing. Aventis is acknowledged for their financial support of the PROTEKT study. 
The data and discussion in the manuscript were presented in part at the European Respiratory Society Congress held in Glasgow in 2004 (Abstract P3902).

\section{References}

I. WHO: The World Health Report 2002. Reducing risks, promoting healthy life. Volume MDI.WHR.202.A. Geneva, The World Health Organization; 2002.

2. Gross NJ: The GOLD standard for chronic obstructive pulmonary disease. Am J Respir Crit Care Med 200I, I 63(5): 1047-1048.

3. GOLD: Global Initiative for Chronic Obstructive Lung Disease. http://wwwgoldcopdcom/ 2003.

4. ATS: Standards for the diagnosis and care of patients with chronic obstructive pulmonary disease. American Thoracic Society. Am J Respir Crit Care Med 1995, I 52(5 Pt 2):S77-I2I.

5. Gump DW, Phillips CA, Forsyth BR, Mclntosh K, Lamborn KR, Stouch WH: Role of infection in chronic bronchitis. Am Rev Respir Dis 1976, I I3(4):465-474.

6. Buscho RO, Saxtan D, Shultz PS, Finch E, Mufson MA: Infections with viruses and Mycoplasma pneumoniae during exacerbations of chronic bronchitis. J Infect Dis 1978, I37(4):377-383.

7. Smith CB, Golden CA, Kanner RE, Renzetti ADJ: Association of viral and Mycoplasma pneumoniae infections with acute respiratory illness in patients with chronic obstructive pulmonary diseases. Am Rev Respir Dis 1980, I 2 I (2):225-232.

8. Blasi F, Legnani D, Lombardo VM, Negretto GG, Magliano E, Pozzoli R, Chiodo F, Fasoli A, Allegra L: Chlamydia pneumoniae infection in acute exacerbations of COPD. Eur Respir J I993, 6(I): 19-22.

9. Miyashita N, Niki Y, Nakajima M, Kawane H, Matsushima T: Chlamydia pneumoniae infection in patients with diffuse panbronchiolitis and COPD. Chest 1998, I | 4(4):969-97|

10. Sethi S: Infectious exacerbations of chronic bronchitis: diagnosis and management. J Antimicrob Chemother 1999, 43 Suppl A:97-105.

II. Saint S, Bent S, Vittinghoff E, Grady D: Antibiotics in chronic obstructive pulmonary disease exacerbations. A meta-analysis. Jama 1995, 273(1 2):957-960.

12. Allegra L, Blasi F, de Bernardi B, Cosentini R, Tarsia P: Antibiotic treatment and baseline severity of disease in acute exacerbations of chronic bronchitis: a re-evaluation of previously published data of a placebo-controlled randomized study. Pulm Pharmacol Ther 200I, I 4(2): I49-I55.

13. Anthonisen NR, Manfreda J, Warren CPW, Hershfield ES, Harding GKM, Nelson NA: Antibiotic Therapy in Exacerbations of Chronic Obstructive Pulmonary Disease. Annals of Internal Medicine 1987, 106:196-204.

14. Wilson R, Schentag JJ, Ball P, Mandell L: A comparison of gemifloxacin and clarithromycin in acute exacerbations of chronic bronchitis and long-term clinical outcomes. Clin Ther 2002, 24(4):639-652.

15. Spencer S, Jones PW, Group GLOBES: Time course of recovery of health status following an infective exacerbation of chronic bronchitis. Thorax 2003, 58(7):589-593.

16. Sethi S, Murphy TF: Bacterial infection in chronic obstructive pulmonary disease in 2000: a state-of-the-art review. Clin Microbiol Rev 200I, I4(2):336-363.

17. Destache CJ: Optimizing economic outcomes in acute exacerbations of chronic bronchitis. Pharmacotherapy 2002, 22(I Pt 2): I2S-I7S; discussion 30S-32S.

18. Hoban D, Felmingham D: The PROTEKT surveillance study: antimicrobial susceptibility of Haemophilus influenzae and Moraxella catarrhalis from community-acquired respiratory tract infections. J Antimicrob Chemother 2002, 50 Suppl SI:49-59.

19. Jacobs MR, Felmingham D, Appelbaum PC, Gruneberg RN: The Alexander Project 1998-2000: susceptibility of pathogens isolated from community-acquired respiratory tract infection to commonly used antimicrobial agents. I Antimicrob Chemother 2003, 52(2):229-246.

20. Douthwaite S, Hansen LH, Mauvais P: Macrolide-ketolide inhibition of MLS-resistant ribosomes is improved by alternative drug interaction with domain II of 235 rRNA. Mol Microbiol 2000, 36(I): 183-193.

21. Zhong $P$, Shortridge VD: The role of efflux in macrolide resistance. Drug Resist Updat 2000, 3(6):325-329.
22. Farrell DJ, Morrissey I, Bakker S, Felmingham D: Molecular characterization of macrolide resistance mechanisms among Streptococcus pneumoniae and Streptococcus pyogenes isolated from the PROTEKT 1999-2000 study. J Antimicrob Chemother 2002, 50 SuppI S I:39-47.

23. Farrell DJ, Douthwaite S, Morrissey I, Bakker S, Poehlsgaard J, Jakobsen L, Felmingham D: Macrolide Resistance by Ribosomal Mutation in Clinical Isolates of Streptococcus pneumoniae from the PROTEKT 1999-2000 Study. Antimicrob Agents Chemother 2003, 47(6): $1777-1783$.

24. Felmingham $D$ : The need for antimicrobial resistance surveillance. J Antimicrob Chemother 2002, 50(90002): I-7.

25. NCCLS: Methods for dilution antimicrobial susceptibility tests for bacteria that grow aerobically; Approved Standard - Fifth Edition. NCCLS document M7 - A5. Wayne, Pennsylvania 19087 - 1898, USA ; 2000.

26. NCCLS: Performance standards antimicrobial susceptibility testing; Twelfth information supplement. NCCLS document MI 00 - I 2. Wayne, Pennsylvania 19807 - I898, USA, NCCLS; 2002.

27. NCCLS: Performance standards antimicrobial susceptibility testing; Twelfth information supplement.NCCLS document MI00-S I 4. Wayne, Pennsylvania 19807 - 1898, USA, NCCLS; 2004.

28. Sethi S: Infectious etiology of acute exacerbations of chronic bronchitis. Chest 2000, I I 7(5 Suppl 2):380S-5S.

29. Tager I, Speizer FE: Role of infection in chronic bronchitis. N Engl J Med 1975, 292(I I):563-57I.

30. Murphy TF, Sethi S: Bacterial infection in chronic obstructive pulmonary disease. Am Rev Respir Dis 1992, I 46(4): I067-I 083.

31. Isada CM: Pro: antibiotics for chronic bronchitis with exacerbations. Semin Respir Infect 1993, 8(4):243-253.

32. Sethi S: The Role of Antibiotics in Acute Exacerbations of Chronic Obstructive Pulmonary Disease. Curr Infect Dis Rep 2003, 5(I):9-15.

33. Sethi S, Evans N, Grant BJ, Murphy TF: New strains of bacteria and exacerbations of chronic obstructive pulmonary disease. N Engl J Med 2002, 347(7):465-47I.

34. Moellering RC]: Meeting the challenges of beta-lactamases. J Antimicrob Chemother 1993, 3 I Suppl A: I-8.

35. Scheld WM: Maintaining fluoroquinolone class efficacy: review of influencing factors. Emerg Infect Dis 2003, 9(I): I-9.

36. Nord CE, Farrell DJ, Leclercq R: Impact of ketolides on resistance selection and ecologic effects during treatment for respiratory tract infections. Microb Drug Resist 2004, I 0(3):255-263.

37. Miyashita N, Fukano $H$, Niki $Y$, Matsushima T: In vitro activity of telithromycin, a new ketolide, against Chlamydia pneumoniae. J Antimicrob Chemother 2001, 48(3):403-405.

38. Edelstein PH, Edelstein MA: In vitro activity of the ketolide HMR 3647 (RU 6647) for Legionella spp., its pharmacokinetics in guinea pigs, and use of the drug to treat guinea pigs with Legionella pneumophila pneumonia. Antimicrob Agents Chemother 1999, 43(I):90-95.

39. Hammerschlag MR, Roblin PM, Bebear CM: Activity of telithromycin, a new ketolide antibacterial, against atypical and intracellular respiratory tract pathogens. J Antimicrob Chemother 200I, 48 Suppl TI:25-3I.

40. Khair OA, Andrews JM, Honeybourne D, Jevons G, Vacheron F, Wise R: Lung concentrations of telithromycin after oral dosing. $J$ Antimicrob Chemother 200I, 47(6):837-840.

41. Nicolau DP: Predicting antibacterial response from pharmacodynamic and pharmacokinetic profiles. Infection 200I, 29 Suppl 2: II-I5.

42. Edlund C, Alvan G, Barkholt L, Vacheron F, Nord CE: Pharmacokinetics and comparative effects of telithromycin (HMR 3647) and clarithromycin on the oropharyngeal and intestinal microflora. J Antimicrob Chemother 2000, 46(5):741-749.

43. Aubier M, Aldons PM, Leak A, McKeith DD, Leroy B, Rangaraju M, Bienfait-Beuzon C: Telithromycin is as effective as amoxicillin/ clavulanate in acute exacerbations of chronic bronchitis. Respir Med 2002, 96( I I):862-87I.

44. Zhanel GG, Walters M, Noreddin A, Vercaigne LM, Wierzbowski A, Embil JM, Gin AS, Douthwaite S, Hoban DJ: The ketolides: a critical review. Drugs 2002, 62(I 2): |77|-1804. 